\title{
Epilepsy in Papua New Guinea: a longitudinal cohort study
}

\author{
Casparia Mond, ${ }_{1}^{1}$ Trevor Duke, ${ }^{2,3}$ John Vince ${ }^{4}$
}

'Paediatric Department, Port Moresby General Hospital, Port Moresby, Papua New Guinea Intensive Care Unit and University of Melbourne Department of Paediatrics, Royal Childrens Hospital, Parkville, Victoria, Australia ${ }^{3}$ Department of Child Health, School of Medicine and Health Sciences, University of Papua New Guinea, Port Moresby, Papua New Guinea

${ }^{4}$ Department of Clinical Sciences, University of Papua New Guinea, Port Moresby, Papua New Guinea

\section{Correspondence to}

Professor Trevor Duke, Intensive Care Unit and University of Melbourne, Department of Paediatrics, Royal Childrens Hospital, Parkville, VIC 3010 Australia ;

trevor.duke@rch.org.au

Received 11 March 2019 Revised 2 June 2019 Accepted 30 June 2019 Published Online First 19 July 2019

\section{ABSTRACT}

Epilepsy affects up to $1-4 \%$ of children living in low income and middle countries, however there are few studies of the problems faced by children with epilepsy in such settings. We aimed to document the situation for children with epilepsy in Port Moresby, an urban area in Papua New Guinea, a low-middle income country in the Western Pacific region. We conducted longitudinal cohort study using mixed methods, with serial data collected over 2 years which assessed seizure control, neurodevelopment, and structured interviews with children and parents. For quantitative data descriptive statistics are reported; for qualitative data common responses, themes, experiences and perceptions were grouped and reported in narrative. Forty-seven children with epilepsy were followed for a median of 18 months. Twenty six (55\%) children had some associated neurodevelopmental disability. Children gave detailed and vivid descriptions of their experience of seizures. Most children and parents had a positive view of the future but faced many challenges including financial difficulties, fear of having seizures especially at school, restriction of activity that isolated them from peers, and significant stigma and discrimination. Seizure control improved over time for some children, but inconsistent supply of phenobarbitone hindered better control. Comprehensive care for children with epilepsy requires a good knowledge of the individual patient -including their seizure type and comorbidities, their family, and their strengths and vulnerabilities. Children with epilepsy face many problems that can lead to isolation, discrimination and restricted opportunities.

\section{INTRODUCTION}

Epilepsy is the most common neurological disorder in children with prevalence estimates in low-income countries varying from 3.6 to 44 per 1000 in children. ${ }^{1-3}$ WHO estimates that $80 \%$ of affected children live in countries with limited resources, and the treatment gap where affected children are not consistently treated is estimated at greater than $60 \% .^{4-6}$ The consequences of inadequate treatment are often severe. These include preventable seizures and secondary injury from falls, burns and drowning. ${ }^{5}$ Furthermore, many children with epilepsy suffer loss of potential for education and development and have suboptimal school and community participation. There are significant mental health consequences of having poorly controlled seizures, including anxiety and fear, isolation from peers and feelings of stigma and discrimination for affected children and their families. ${ }^{7}$ Poor control of seizures or inadequate treatment of people with epilepsy increases the risk for sudden unexpected death in epilepsy, a rare but poorly understood complication. ${ }^{8}$

Little is known about epilepsy and its comorbidities in children in Papua New Guinea (PNG) or Pacific Island communities. There has been only one previous study from PNG: a prospective study of 40 children at Port Moresby General Hospital (PMGH) in 1990-1991. ${ }^{9}$ Our aim was to follow a cohort of children with epilepsy and document its nature and extent, associated comorbidities, access to treatment, the adequacy of seizure control, the quality of life and developmental opportunities and the difficulties faced by them and their families.

\section{METHODOLOGY}

We conducted a longitudinal cohort study using mixed methods with serial data collection for up to 2 years. Children between the ages of 1 years and 18 years with epilepsy who attended PMGH were included in this study. Children were recruited from the outpatients department, the children's wards, the emergency department and the neurology clinic. Epilepsy was defined according to the standard international definitions of the International League Against Epilepsy. ${ }^{10}$ Children entered the study after their parents gave written consent. The parents were interviewed using a structured questionnaire with closed and open questions. Children who were old enough and had the communication skills to answer questions were also interviewed if they and their parents consented.

The questionnaire was designed to obtain baseline demographic data, a description of the convulsions to enable classification the anti-epileptic drugs (AED) given to the child, and issues associated with access to and effectiveness of AEDs, and additional medical care required by the child. We sought to understand parental concerns and challenges faced in caring for their child and the extent and challenges of school participation.

The children's questionnaire contained questions about the child's perception of his or her illness and why the AED was taken, as well as questions about stigma or discrimination they may have experienced, and their hopes for their future.

Interviews were conducted in English or Tok Pisin as appropriate. Some interviews were recorded electronically and were later transcribed if consent was given for this. A neurodevelopment assessment included motor, visual, hearing, speech and language assessment using the Denver II Developmental Assessment for children aged 1-6 years. 
For older children, a neurological examination was done and neurological impairments documented.

The parents or guardians of 28 children were given a diary. Those not given diaries were either illiterate or felt they would not use the diary as their child did not have frequent seizures. The diary was used to record the number, type and duration of seizures, any aura the child may have experienced, if anticonvulsants were missed and the reasons why. Problems with school attendance and any other problem or questions the parents might wish to ask the doctor at the next review were also to be noted. These were reviewed at each follow-up session and the content noted.

The degree of seizure control was classified as good (1-4 seizures per month), moderately controlled (5-10 seizures per month) or poorly controlled seizures (11-30 seizures per month). This was assessed at each follow-up review, every 1-3 months.

\section{Follow-up}

Reviews occurred monthly if the seizures were poorly controlled, or every 2-3 months for other children, depending on parents' availability and the distance they lived from the hospital.

\section{Analysis}

Quantitative data were entered into an Excel spread sheet and analysed descriptively: population medians and IQRs, and proportions. Qualitative responses were grouped under common themes and reported with a narrative description of expressed experiences and perceptions and verbatim responses.

\section{Ethics approval}

Written informed consent was gained from parents of all children involved.

\section{RESULTS}

The cohort consisted of 47 children with epilepsy, of which 25 were female. Table 1 describes the characteristics of these children. The median age was 6.5 years (IQR 5.5-12 years).

\begin{tabular}{ll}
\hline Table $1 \quad$ Patient characteristics and comorbidities & \\
\hline Patients (n=47) & \\
\hline Median age (years) (IQR) & $6.5(5.5-12)$ \\
\hline Male: female & $22: 25$ \\
\hline Normal development for age (\%) & $21(45)$ \\
\hline Comorbidities & No. (\%) \\
\hline Gross motor dysfunction & $20(42)$ \\
\hline Hypotonia & $1(2)$ \\
\hline Hypertonia & $3(6)$ \\
\hline Haemiplegia or monoplegia & $11(23)$ \\
\hline Spastic quadriparesis & $5(11)$ \\
\hline Fine motor skills delay & $14(30)$ \\
\hline Vision impairment & $4(9)$ \\
\hline Speech impairment & $16(34)$ \\
\hline Hearing impairment & $2(4)$ \\
\hline Behaviour problems or neurodevelopmental comorbidities & $18(38)$ \\
\hline Hyperactive & $11(23)$ \\
\hline Mental health/psychosis & $4(9)$ \\
\hline Poorly responsive & $3(6)$ \\
\hline Difficulty feeding & $9(19)$ \\
\hline & $6(13)$ \\
\hline
\end{tabular}

Table 2 Seizure types and antiepileptic drugs

\begin{tabular}{ll}
\hline Types of seizures & $\begin{array}{l}\text { Number of patients } \\
\mathbf{n}=47(\%)\end{array}$ \\
\hline Generalised tonic-clonic & $24(51)$ \\
\hline Tonic & $3(6)$ \\
\hline Myoclonic & $2(4)$ \\
\hline Partial simple & $2(4)$ \\
\hline Atonic & $1(2)$ \\
\hline Absence & $1(2)$ \\
\hline Partial complex & $0(0)$ \\
\hline Combination of seizure types & $14(31)$ \\
\hline Antiepileptic drugs & \\
\hline Phenobarbitone monotherapy & $33(70)$ \\
\hline Phenytoin monotherapy & $1(2)$ \\
\hline Sodium valproate monotherapy & $1(2)$ \\
\hline Diazepam monotherapy & $1(2)$ \\
\hline Carbamazepine monotherapy & $0(0)$ \\
\hline More than one AED: mostly phenobarbitone and & $11(23)$ \\
carbamazepine & \\
\hline
\end{tabular}

Twenty-one children had normal development for their age. Eleven had gross motor dysfunction and 14 had delayed fine motor skills. Four had visual impairment and two had hearing impairment. Nine had global developmental delay.

Table 2 documents the seizure types and AEDs used by the children at baseline. The majority $(70 \%)$ were taking phenobarbitone monotherapy.

Table 3 documents the severity of the epilepsy and seizure control at baseline and follow-up. At recruitment, 35 (74\%) children were classified as having good seizure control, and $5(11 \%)$ had moderately well controlled seizures. Two children had poorly controlled seizures and five (115) children were considered to have very poor control having more than 30 seizures a month.

Five children had been injured during seizures, including a flame burn of the arm and facial injuries and several had scars from lacerations from falls and from tongue and finger biting.

Only 3 of the 28 parents who were given diaries used them and brought them regularly to the clinic. These three parents found the diary useful enough to keep using it consistently throughout the follow-up period. They recorded their child's seizures, visits to the physiotherapist, the problems they faced and their questions. AEDs were also adjusted based on the diary notes.

\section{School attendance}

Only $9(26 \%)$ of the 35 school-aged children were attending primary school at the time of study recruitment. None were in high school. One had completed primary school (grade 8 at age 16 years) 2 years prior to this study and was at home planning to start a small business. Sixteen children had been enrolled at primary or elementary schools in the past but had ceased

Table 3 Seizure control at baseline and follow-up

\begin{tabular}{|c|c|c|c|c|c|}
\hline & Baseline & 5 months & 10 months & 15 months & 20 months \\
\hline Seizures/month & $n=47(\%)$ & $\mathrm{n}=47(\%)$ & $\mathrm{n}=42(\%)$ & $\mathrm{n}=43(\%)$ & $\mathrm{n}=23(\%)$ \\
\hline Good $<1-4$ & 35 (74) & $36(77)$ & $35(83)$ & $23(88)$ & $21(92)$ \\
\hline Moderate 5-10 & $5(11)$ & $5(11)$ & $3(7)$ & $1(4)$ & $1(4)$ \\
\hline Poor $11-30$ & $2(4)$ & $4(8)$ & $4(10)$ & $2(8)$ & $1(4)$ \\
\hline Very poor $>30$ & $5(10)$ & $2(4)$ & 0 & 0 & 0 \\
\hline
\end{tabular}


attending because they had a seizure at school. Many parents feared further seizures in school with no family member to help the child. Some children had been withdrawn from school partly because of hyperactivity or being unable to concentrate in class.

\section{Children's interviews}

Seventeen children between 7 and 18 years were interviewed. Box 1 lists the questions asked and some of the verbatim answers. Most children were able to give a description of their seizures or what they felt at the onset of seizures. For example, five (29\%) children said they had headaches or felt heaviness of the head, and three children described blurred vision and dizziness. Some gave descriptions such as 'teeth locked' or 'legs stiff'. Children were also asked if they knew what epilepsy was and over half of them responded that they had some sickness in the head and would shake ('guria guria').

The children were asked what they liked or did not like about school. Of the 17 children interviewed, 9 were attending school at the time they were interviewed, 5 had been to school previously and 3 had never been to school. They nominated the following reasons for enjoying school: because they had friends at school, because they liked certain subjects at school such as English, science, reading and writing, one child liked playing sports at school and two liked going to school because they liked their teachers. A 7-year-old boy in first grade stated that he liked going to school because his teacher let him sharpen his pencils with the large sharpener in his classroom.

Questions about whether they were treated differently by their family, friends or teachers were answered by 15 children. Two children just smiled when asked but did not reply. Fourteen of the 15 children (93\%) who answered said they were treated differently by their friends and family because they had epilepsy. They all had some restrictions placed on them by their parents so they could not go out and play as often as their siblings and were restricted from spending time away from their homes such as spending a weekend away at a friend's or relative's house.

All the children expressed their wish to have few or no restrictions placed on them. They did not like to be teased. Only one child mentioned that the restrictions were for his own good so he accepted them although he was unhappy at times as a result.

In response to the question 'What would you like to be when you are older?', most of the children were enthusiastic about the future. Twelve children knew what they wanted to do in the future, while four children said they did not know and three children did not answer the question. Five children wanted to be doctors, while other's choices were a pastor, a lawyer, a pilot and a fisherman. One wanted to work with computers, and one wanted to work in an office and write in books.

Children were asked about any worries or concerns they may have. Sixteen children answered this question. Worries and concerns were mostly related to epilepsy, their family or school. Five children had worries directly related to epilepsy, wanting their seizures to stop for good.

\section{Parents' interviews}

The 47 children in this study had either one or both parents or a guardian who participated in answering the parents' questionnaire (see box 1 for indicative verbatim responses). When asked the question 'What do you know about epilepsy?', the parents gave various answers based on what part of the body they thought was affected or what they had read or been told by doctors or from their experiences of seeing their child's seizures. Thirty (64\%) parents answered that epilepsy was some sort of brain disorder. Six children (13\%) had at least one relative who also has or had seizures in the past so their parents believed that epilepsy is an inherited condition. Another four parents (8.5\%) answered that they were not sure what condition their child had and so were not sure what epilepsy was, and four believed that magic or the supernatural was involved.

Parents were asked whether they thought epilepsy was treatable or not. Thirty-three $(70 \%)$ answered that epilepsy was treatable, while four caregivers (9\%) stated that epilepsy was not. Ten $(21 \%)$ parents believed that epilepsy was sometimes but not always treatable.

The parents were also asked what challenges their children faced in attending school. Twenty-four parents whose children had at some point attended school answered this question. Fourteen (58\%) said their child had no challenges in school and the child enjoyed going to school. A 14-year-old girl enjoyed school although she was sometimes teased. Even when her family had no bus fare or lunch money for her and she was told to stay at home, she would walk to school and not worry about the money. Ten (42\%) parents stated that their child faced challenges in school in terms of difficulty learning due to poor memory, being hyperactive in class and being slow in reading or writing. Other parents stated that their children were teased in school, and one child was not allowed to participate in school sports because he had epilepsy.

Forty-six parents answered the question on challenges they faced. The main challenges were financial, the constant care required, their child's behaviours and stigma. Some parents expressed multiple challenges others did not find caring for their child a challenge.

Thirteen parents $(28 \%)$ identified financial challenges as the main one. They found it difficult to buy AEDs when the hospital pharmacy ran out, and they also faced challenges with bus fare and care of the child especially when going for monthly clinic or physiotherapy visits. The cost of phenobarbitone in private pharmacies ranged from K36.00 to K210.00 per month (US\$9-52). Parents of children with disabilities had higher financial challenges. A major challenge for some of the parents was always having someone to watch the child in case of a seizure or an accident. Nine parents (20\%) mentioned this as their main challenge. Nine $(20 \%)$ of parents reported their child's behaviour (hyperactivity, offensive language, tantrums and difficulty following instructions) as their main challenge. Three parents had to leave work to stay home and watch their hyperactive child in case the child got hurt while playing or climbing trees or had a seizure while swimming as they lived near the sea.

Forty-six parents gave their views of their child's future. The majority were positive. Two-thirds stated that the child's future would be fine or good 'em bai orait' (he or she will be ok). Parents of 13 children (29\%) were unsure of their child's future, and two parents (4\%) of children with spastic quadriparesis stated that the future of their child was going to be poor. One grandmother stated sadly 'she must go before me, that's my prayer as there is nobody to care for her apart from me'.

Parents were also asked how the care of their child by the health services could be better. Issues raised were the long waiting time at the hospital pharmacy and the frequent stockouts of phenobarbitone and other AEDs. Many suggestions were around communication and provision of information. Parents spoke of the need for doctors to better explain their child's condition and for doctors to spend time finding our more about the child's condition and to ask about other issues affecting the child instead of just the AEDs and seizures. 
If the response was in Tok Pisin, this is presented first, followed by the English translation.

\section{Children's interviews}

What do you feel when you get sick or have seizures?

- A 16-year-old boy described his experience: 'Mi sa feelim olsem mi no sa lukluk, hard lo lukluk, brain stap lo narapela hap, mi sa harim ol man toktok but sik controlim brain blo mi na mi hard lo toktok' (I feel like I cannot see, it's hard to see, my brain is somewhere else, I can hear people talking but the sickness has controlled my brain so I cannot talk).

- One child described what she experiences: 'Mi sa guria guria, tupla ear drum hot na brain sa move inside lo het' (I shake, my two ear drums are hot and my brain moves inside my head)

- Two children who had palpitations or mild chest pain prior to a seizure describe epilepsy as being related to the heart. One of these, a 9-year-old child said 'lewa blo mi sa kisim shock' (my heart gets a shock).

- A 15-year-old girl stated 'em mas lek blo mi sik bikos em start olgeta taim lo lek na spread go lo het na mi blackout. Lek blo mi sa tait na mi sa sigaut bikos mi laik pudaun' (it must be my leg that's sick because it always starts with my leg and spreads to my head and then I black out. My legs becomes stiff and I scream because I am going to fall down.)

What do you think about school?

- A 17-year-old who completed only 1 year of elementary school at age 8 years said 'Mi laik go skul but mi no sa harim toktok blo teacher na ol mangi sa tok 'longlong" (I wanted to go to school but I never listened to what the teacher said and the kids would call me dumb)

- A 14 year-old in fifth grade said 'mi laik kisim save na mi bai wok na lukautim mama na papa' (I want to get educated so I can get a job and take care of my parents).

Are you treated differently by friends or family because of your epilepsy?

- One 9-year-old boy who likes to play with his friends said 'mama stopim mi lo go play na sa ok yu sikman ya stap lo haus, mi sa belhat. Ol sa givim mi moni na mi sa stap lo haus' (Mum stops me from going to play and says you are a sick person so stay at home and I get angry. They (family) give me money so that I can stay home).

- An 11-year-old boy said 'mum and dad stop me from playing and my brother calls me "sick dog". My friends at school tease me and I hit them sometimes'.

- A 14-year-old girl in grade 5 stated that her family do not allow her to go to her friends' and relatives' homes. Boys at school tease her and call her 'guria guria meri' (shake shake girl) and imitate her seizures as she has had several seizures at school since she started school.

- Another 16-year-old boy in grade 8 is teased by kids in his village a lot and they call him 'sik muruk' (another term for seizure or epilepsy in Tok Pisin).

- One girl who was usually teased and isolated by her two younger sisters said 'Ol sister blo mi mas lukautim mi na mipla play wantaim' (my sisters should take care of me and we play together).

What were their worries or concerns?

- Two children were concerned about school. One 16-year-old girl who was in the last year of primary school (grade 8) was worried she would not be allowed by her parents to go to high school as her classmates would not know what to do if she had a seizure in high school. Her friends at her current school know what to do and have helped her in the past when she had seizures at school. Another 15-year-old girl was worried she could not trust her friends at school as they would go out with boys they knew she liked.

- Five children had worries concerning their family. A 14-year-old girl worried a lot about her deceased grandmother as her grandmother had help raise her and had passed away 3 years prior. An 11 -year-old boy missed his mother who lived in another province. A 9-yearold boy who lived with his mother was worried that his father did not care for him as his father had divorced his mother and started another family.

\section{Parent's interview}

What do you know about epilepsy?

- Most parents stated that something was wrong with the brain itself 'em sik lo brain' (it's a sickness of the brain) or 'em gat sik lo het' (he has a sickness of the head). Parents of four children thought it affected the brain because of worry or psychological problems in the child, and three parents said it was post infection such as cerebral malaria or meningitis.

- One parent who thought epilepsy occurs postinfection said 'ol mosquito putim kiau lo head blo em taim em baby na em kisim malaria lo brain na bihain kisim displa sik' (mosquitoes laid their eggs in her brain when she was a baby and she got malaria in her brain then later got this sickness - epilepsy.

- Four parents believed that the origin of their child's epilepsy is not medical but has a supernatural origin. One parent stated 'ol man lo ples bagarapim em' (he has been cursed by people in our village).

- Three parents whose children always had generalised tonic clinic seizures believed that epilepsy was a condition that affected the whole body because their seizures affected their whole body. A mother of a 10-year-old said 'olgeta body blo em sa move taim em fit so sik so olgeta body em displa sik affectim' (the whole body moves when he has a fit therefore this sickness affects the whole body).

Main challenges faced by parents

- One parent of a 16-year-old who has quadriplegia (and the fourth of five children) said 'it's (finances) a very big challenge. We have difficulty feeding her three meals a day as she is bigger now and eats a lot. We cannot afford transport to take her with the wheelchair for physiotherapy weekly'. 
- Parents of two (4\%) children felt that their main challenge was the stigma they perceived from the community. One parent of a 3-yearold child said 'we don't want people to say that we have a child with this sickness'.

How can healthcare for the child be better?

- One parent stated 'doctors have to spend more time with the patient and parents and encourage them to put their children in school so parents won't be afraid'. Another parent said 'Doctors follow-up in terms of medicine but finding out more about the patient will make the parents feel like they are concerned'. One parent whose child cannot speak said 'pikinini blo mi ino sa toktok so dokta mas askim mi more lo wanem needs blo pikinini, ino raitim marasin tasol' (my child doesn't speak so the doctor should ask me more about what the child's needs are and not just write the medicine (prescription)).

\section{Follow-up}

The 47 children were followed up for 15-20 months depending on the date of recruitment into the study. Each child was seen monthly, every second or every third month depending on the parents' availability and how far they lived from the hospital. There was improved seizure control for some children throughout the follow-up period, with a greater proportion of children having good control and a lower proportion of children having poor or very poor control (table 3). However, none of these differences reached statistical significance.

\section{DISCUSSION}

There are few longitudinal studies of epilepsy in low-income and middle-income countries, ${ }^{11-13}$ and we could not find any other longitudinal epilepsy studies specifically focused on children in these settings. This is only the second study in the Asia Pacific region to assess the adequacy of seizure control over time and the perceptions and aspects of quality of life for children with epilepsy and their families; the other study was a cross-sectional study from Malaysia. ${ }^{14}$ The follow-up period in our study averaged 18 months, sufficient to document outcomes, the challenges faced by children and their families and the aspects of care that need to be considered in providing services that meet their needs. The study demonstrated children's knowledge, ideas and understanding related to their epilepsy, their experience of seizures, their concerns regarding stigma and restrictions placed on their activity, the risk of injury during seizures and the importance of their self-esteem in going to school despite difficulties. Some children volunteered vivid descriptions of their seizures and any aura they experienced. To our knowledge, this has not been described in a systematic way before and gives insights into their experiences and explains some perceptions and fears.

We cannot say that this cohort is representative of all children with epilepsy in PNG. Our cohort may include a higher proportion of children with neurodevelopmental delay because we recruited children attending a tertiary hospital, but it also may include a higher proportion of children attending school than children with epilepsy in rural provinces. No families declined to participate, and we did not exclude families on the basis of lack of literacy or declining to use a seizure diary, for example. We conducted interviews in Tok Pisin, so parents who did not speak English were represented. Girls with epilepsy were well represented in our cohort. A cohort enrolled using multicommunity sampling may be more representative, and this would in addition enable a population prevalence of childhood epilepsy to be estimated, but we did not have the resources for such a study. In the National Capital District, most families from the settlements and other economically deprived areas can and do access health services through PMGH.

In studies in low-income and middle-income countries, belief that sorcery or witchcraft is a cause of epilepsy is often cited. ${ }^{15-17}$
While the majority of parents in our study indicated that epilepsy was a brain disorder or an inherited problem, four were not sure of the cause, and another four said they thought some magic was involved. A belief in sorcery was not commonly voiced by the parents in our study, but it was volunteered by some, and may be more common in some less informed segments of their communities, and contribute to stigmatisation.

WHO recommends phenobarbitone as the first drug of choice for most seizures and epilepsies in developing countries because of its low cost and general effectiveness ${ }^{18}$ and is on the essential drug list of $95 \%$ countries surveyed by WHO. ${ }^{19}$ In our cohort, seizure control was affected by the inconsistent supply of phenobarbitone at the public hospital pharmacy at PMGH. Many parents could not afford to purchase phenobarbitone through private pharmacies. Phenytoin, carbamazepine and sodium valproate are also on the WHO essential drug list. ${ }^{20}$ However, sodium valproate was not available at the public pharmacy, and it was very costly to purchase elsewhere. It is essential that second-line therapy be consistently available and affordable, as not all children will respond to phenobarbitone and side effects are often limiting. Similar problems have been shown in other low-resource settings. ${ }^{21}$

Nearly three-quarters of the children in this study had good seizure control based on the classification we used of $0-4$ seizures per month. There are no standardised internationally accepted classification systems for assessing degree of control. Ours was an arbitrary and very basic classification. The number of seizures is not the only measure of adequacy of control, and duration of seizure and seizure type are important aspects to consider. There was a trend to improved seizure control over time, with fewer children having poor or very poor control of seizures after 18 months follow-up.

Previous studies of the use of seizure diaries in children, especially with multiple complex seizure types, identified limited reporting. ${ }^{22}$ There are no studies that we could find of the use of seizure diaries in low-resource settings. Utilisation of the seizure diaries in our cohort was similarly limited, the diary being used regularly for only three children. The use of a diary requires a degree of literacy, and for families that are not literate, some other way of recording the seizures could be devised.

Most children with epilepsy can go to school with support from their family if their seizures are controlled and any associated complications are managed well. The parents in our study feared that seizures would occur at school and that the child would not cope in school due to distractibility or hyperactivity. Having a simple plan written and discussed with the teacher and having emergency contacts at the school can help. A letter from the doctor informing the teacher of the child's condition and what to do in the case of a seizure will also help. Despite parents' feelings about their children's challenges at 
school and some experience of stigma, almost all the children interviewed enjoyed attending school.

Many parents stated that they would like the doctors to better explain their child's condition, spend time finding out more about the child's condition and also discuss issues in addition to the AEDs. One study found that key challenges for parents were the disclosure of epilepsy and the lack of adequate psychosocial and emotional support. ${ }^{23}$ Parents of children with chronic conditions require time to discuss their child's issues and doctors may not be able to provide the amount of time required. Parents and children also require easy access to support services such as social workers and physiotherapists. One mother in our study suggested having a multidisciplinary epilepsy clinic including a paediatrician, social worker and physiotherapist. Paediatric nurses could run the clinic and a pharmacist could also be involved to assist with drug supply issues or complications of AEDs. Nurses trained in epilepsy has worked in other multidisciplinary approaches, and this may be an appropriate and practical model to work towards. ${ }^{24}$

\section{CONCLUSIONS}

Comprehensive care for children with epilepsy requires a good knowledge of the individual patient-their condition and comorbidities, their family and their strengths and vulnerabilities. It requires following patients over a long time and ready availability of services directed at the specific needs of the children and their families. The quality of life of a child with epilepsy is not purely the result of epilepsy itself but depends on the child's resilience, parental and family well-being, family attitudes and social and cultural background.

Acknowledgements We would like to thank the patients and their families for participating in the study.

Contributors CM and TD designed the study. CM enrolled the cohort and followed them over 18 months. CM and TD analysed the data. CM wrote the first draft of the manuscript as her masters thesis, TD and JDV supervised the project and revised the manuscript.

Funding This study was supported by the RE Ross Trust (Victoria).

Competing interests None declared.

Patient consent for publication Not required.

Ethics approval Ethics approval was given by the University of Papua New Guinea School of Medicine and Health Science Research Committee.

Provenance and peer review Not commissioned; externally peer reviewed.

\section{REFERENCES}

1 Camfield P, Camfield C. Incidence, prevalence and aetiology of seizures and epilepsy in children. Epileptic Disord 2015;17:117-23.
2 Moshé SL, Perucca E, Ryvlin P, et al. Epilepsy: new advances. Lancet 2015;385:884-98.

3 Pandey S, Singhi P, Bharti B. Prevalence and treatment gap in childhood epilepsy in a north Indian city: a community-based study. J Trop Pediatr 2014;60:118-23.

4 World Health Organization Programme for Neurological Diseases and Neuroscience. Atlas: epilepsy care in the world: World Health Organization, 2005.

5 Newton CR, Garcia HH. Epilepsy in poor regions of the world. The Lancet 2012;380:1193-201.

6 Mbuba CK, Ngugi AK, Fegan G, et al. Risk factors associated with the epilepsy treatment gap in Kilifi, Kenya: a cross-sectional study. Lancet Neurol 2012;11:688-96

7 Howell E. Epilepsy stigma: moving from a global problem to a global solution. Seizure 2010;19:628-9.

8 Levira F, Thurman DJ, Sander JW, et al. Premature mortality of epilepsy in low- and middle-income countries: A systematic review from the Mortality Task Force of the International League Against Epilepsy. Epilepsia 2017;58:6-16.

9 Danaya RT, Johnson FA, Ambihaipahar U. Childhood epilepsy in Papua New Guinea. P N G Med J 1994;37:3-6.

10 Fisher RS, Acevedo C, Arzimanoglou A, et al. ILAE official report: a practical clinical definition of epilepsy. Epilepsia 2014;55:475-82.

11 Berhanu S, Prevett M. Treatment of Epilepsy in Rural Ethiopia: 2 Year Follow-up. Ethiopian Journal of Health Development 2004;18:31-4.

12 Sawhney IM, Singh A, Kaur P, et al. A case control study and one year follow-up of registered epilepsy cases in a resettlement colony of North India, a developing tropical country. J Neurol Sci 1999;165:31-5.

13 Banerjee TK, Ray BK, Das SK, et al. A longitudinal study of epilepsy in Kolkata, India. Epilepsia 2010;51:2384-91.

14 Fong CY, Chang WM, Kong AN, et al. Quality of life in Malaysian children with epilepsy. Epilepsy Behav 2018;80:15-20.

15 Osungbade KO, Siyanbade SL. Myths, misconceptions, and misunderstandings about epilepsy in a Nigerian rural community: implications for community health interventions. Epilepsy Behav 2011;21:425-9.

16 Bain LE, Awah PK, Takougang I, et al. Public awareness, knowledge and practice relating to epilepsy amongst adult residents in rural Cameroon--case study of the Fundong health district. Pan Afr Med J 2013;14.

17 Dolo H, Mandro M, Wonya'Rossi D, et al. Community perceptions of epilepsy and its treatment in an onchocerciasis endemic region in Ituri, Democratic Republic of Congo. Infect Dis Poverty 2018;7:115.

18 Brodie MJ, Kwan P. Current position of phenobarbital in epilepsy and its future. Epilepsia 2012;53:40-6.

19 Mbuba CK, Newton CR. Packages of care for epilepsy in low- and middle-income countries. PLoS Med 2009;6:e1000162.

20 World Health Organization. WHO model list of essential medicines, 20th list (March 2017, amended August 2017), 2017.

21 Katchanov J, Birbeck GL. Epilepsy care guidelines for low- and middle- income countries: from WHO mental health GAP to national programs. BMC Med 2012;10:107.

22 Fisher RS, Blum DE, DiVentura B, et al. Seizure diaries for clinical research and practice: limitations and future prospects. Epilepsy Behav 2012;24:304-10.

23 Kampra M, Tzerakis N, Lund Holm Thomsen L, et al. The challenges that parents of children with epilepsy face: a qualitative study. Epilepsy Behav 2017:71:94-103.

24 Bali A, Hargreaves DS, Cowman J, et al. Integrated care for childhood epilepsy: ongoing challenges and lessons for other long-term conditions. Arch Dis Child 2016;101:1057-62. 